\title{
Socio-economic variables influence the prevalence of inadequate nutrient intake in Brazilian adolescents: results from a population-based survey
}

\author{
Eliseu Verly Junior ${ }^{1}{ }^{*}$, Chester Luis Galvão Cesar ${ }^{2}$, Regina Mara Fisberg ${ }^{1}$ and \\ Dirce Maria Lobo Marchioni ${ }^{1}$ \\ 'Department of Nutrition, School of Public Health, University of São Paulo, Av Doutor Arnaldo 715, \\ PO Box 01246-904, São Paulo, Brazil: ${ }^{2}$ Department of Epidemiology, School of Public Health, \\ University of São Paulo, São Paulo, Brazil
}

\section{Submitted 4 October 2010: Accepted 25 February 2011: First published online 4 May 2011}

\begin{abstract}
Objective: To estimate the prevalence of inadequate nutrient intake among adolescents and the association between socio-economic variables and nutritional status.

Design: Cross-sectional study with a population-based sample.

Settings: The usual nutrient intake distribution was estimated using the Iowa State University method. The Estimated Average Requirement cut-off point method was used to determine the proportion of adolescents with inadequate intake for each nutrient, according to sex, income, parental educational level and nutritional status.

Subjects: Twenty-four-hour dietary recalls were applied in 525 male and female Brazilian adolescents aged 14-18 years.

Results: The highest prevalence of inadequate nutrient intake was observed for vitamin E (99\% in both sexes). For male and female adolescents, the prevalence of inadequate intake was: $\mathrm{Mg}, 89 \%$ and $84 \%$; vitamin $\mathrm{A}, 78 \%$ and $71 \%$; vitamin C, $79 \%$ and $53 \%$; and vitamin $\mathrm{B}_{6}, 21 \%$ and $33 \%$, respectively. The prevalence of inadequate intake for niacin, thiamin, riboflavin, Se, $\mathrm{Cu}$ and vitamin $\mathrm{B}_{12}$ was $<15 \%$. Individuals in the lower income and lower parental educational level strata had the highest risk of having inadequate intake for $\mathrm{P}$, riboflavin and vitamins $\mathrm{A}, \mathrm{B}_{6}$ and $\mathrm{B}_{12}$. Compared with non-overweight individuals, overweight individuals had a higher risk of inadequate intake for $\mathrm{Mg}$, vitamin $\mathrm{A}, \mathrm{P}$, thiamin and riboflavin.

Conclusions: The present study found a high prevalence of inadequate intake of nutrients that are recognised as being protective against chronic diseases. Adolescents in the lower income and lower parental educational level strata were less likely to have their nutrient intake requirements met.
\end{abstract}

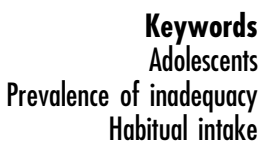

Keywords inadequacy Habitual intake
Optimal micronutrient status is essential not only for the health and psychological well-being of adolescents but also for their growth, long-term health and development. A basic question regarding nutrient inadequacy is: what proportion of the population has usual nutritional intake less than their requirement? In addition, this assessment is needed to verify that intake levels are not so high that they pose a risk of adverse health effects in a group of individuals $^{(1)}$.

Although critically important from the perspective of public health ${ }^{(2)}$, information about the adequacy of nutrient intake is seldom collected for adolescents in developing countries; further, it is often based on small, non-representative samples. In recent decades, diets have changed markedly in Brazil in that the Western diet is replacing the traditional diet, which is based on grains, such as rice, and beans ${ }^{(3)}$.

In addition to the scarcity of published data regarding the prevalence of inadequate nutrient intake in adolescents $^{(4-6)}$, the role of socio-economic factors has not been addressed even though there is evidence that individuals in the lower income and lower educational level strata have less access to a healthy $\operatorname{diet}^{(7)}$.

The aim of the present study was to estimate the prevalence of inadequate nutrient intake among adolescents living in São Paulo, Brazil, who were enrolled in a population-based health survey conducted in 2003. The present study also examined the association between the prevalence of inadequate nutrient intake and family income, parental education and overweight status. 


\section{Methods}

\section{Study population}

The Health Survey for São Paulo (ISA) was a representative sample study conducted from March to December 2003. Details are available elsewhere ${ }^{(8)}$. Briefly, from a total population of 813 adolescents, those in the 14-18-year age range were selected for the study ( $n$ 525; 276 male and 249 female participants). This age group was studied to maintain consistency with the life-stage groups established in the Dietary Reference Intake (DRI) reports ${ }^{(1)}$. The present study was approved by the local ethics committee. Written informed consent was obtained from the participants or, if participants were younger than 18 years of age, from a parent or legal guardian.

\section{Data collection and processing}

Information on food intake, demographics and socio-economic and anthropometric variables was obtained using structured questionnaires through household interviews. Height and weight were self-reported. Categories of income were defined as low income $(<1$ minimum wage per capita) and high income ( $\geq 1$ minimum wage per capita) according to the current minimum wage established by the Brazilian government at the time of data collection*. Parental educational level was defined as the number of years of education completed by the head of the household. Strata were defined as low ( $<8$ full years of education) and high ( $\geq 8$ full years of education). Overweight status was assessed using the recommended BMI for sex and age and the cut-off points proposed for adolescents ${ }^{(9)}$.

A multiple-pass $24 \mathrm{~h}$ recall $(24 \mathrm{HR}$ ) was administered by trained interviewers. This method differs from the traditional 24HR because the interviewer uses three distinct steps to collect information about a participant's food intake. In the first step, respondents are asked to recall everything they ate the previous day. In the second step, respondents are asked to clarify any foods mentioned in the previous step. Finally, in the third step, the interviewer reviews the list of foods mentioned and probes for additional eating occasions ${ }^{(10)}$. The sampling days for all participants covered all the days of the week. Foods reported in each $24 \mathrm{HR}$ were critically reviewed to identify any failures related to the descriptions of the food consumed or to food preparation techniques, including their apportioning and quantification. The data were analysed for eighteen nutrients using Nutrition Data System for Research software version 2007 (Nutrition Coordinating Center, University of Minnesota, Minneapolis, MN, USA). Additional interview questions were asked to assess supplement use. However, because of the low rate of supplement use $(4 \cdot 5 \%)$, this information was not computed in the total nutrient intake.

* Between April 2003 and March 2004, the monthly minimum wage in Brazil was equivalent to \$US $109 \cdot 90$ (based on the exchange rate on 29 April 2003).

\section{Dietary data and statistical analysis}

Usual intake was estimated by adjusting for the withinperson variance of the nutrient intake using the Iowa State University (ISU) method ${ }^{(11)}$. This method can be used when two or more $24 \mathrm{HR}$ are available for at least a subsample of the individuals. Because applying the Estimated Average Requirement (EAR) cut-off point method to the unadjusted nutrient distributions will result in biased prevalence estimates, we considered the external estimates of within-person variance components as a reasonable approach ${ }^{(12,13)}$. Accordingly, as the ISA-2003 data collection protocol included only a single $24 \mathrm{HR}$, further data were collected to provide estimates of the within- and between-person variability. All adolescents who participated in the ISA-2003 survey and who were younger than 19 years of age at the beginning of the new data collection (March 2007) were invited to answer two additional 24HR. Among the 328 adolescents (168 male and 160 female) who met these criteria, 146 answered two additional $24 \mathrm{HR}$ within a 2-month interval and sixty-eight answered only one additional 24HR. The within-person variance component and the fourth moment of the nutrient intake distribution for each nutrient and sex combination were estimated from these data, and such external parameters were applied to the ISA-2003 data set to estimate the distribution of the usual nutrient intake. The fourth moment is a measure of flatness of a distribution, also referred to as kurtosis. This procedure was implemented using the personal computer version of Software for Intake Distribution Estimation version $1 \cdot 0$ (PC-SIDE; Department of Statistics, ISU, Ames, IA, USA). The PC-SIDE software calculates an empirical estimate and adjusted percentiles of the usual nutrient intake within each EAR age and sex subgroup; the software also calculates the prevalence of inadequate intake on the basis of the subgroup EAR cut-off point method. This method was endorsed by Dwyer et al. ${ }^{(14)}$ and Hoffman et al. ${ }^{(15)}$. The statistical model for each nutrient and sex group included the day of the week (dichotomised into weekdays and weekend days) and month of the year as covariates. Owing to the complex sampling design of the survey, sampling weights were also included in the model.

\section{The Estimated Average Requirement cut-off point metbod}

The values proposed by the Institute of Medicine (IOM) ${ }^{(1)}$ were used as the reference for nutrient intake. The prevalence of inadequate nutrient intake was assessed by the EAR cut-off point method. In this method, the prevalence of inadequate intake is estimated as the proportion of the population with usual intakes below the median requirement $(\mathrm{EAR})^{(1,16)}$. In the case of nutrients such as vitamins D and $\mathrm{K}, \mathrm{K}$ and $\mathrm{Ca}$, for which there is not enough information to set an EAR cut-off point value, the distribution of intake was estimated and compared with the Adequate Intake (AI). For these nutrients, we calculated the proportion 
Table 1 Recommended nutrient intake, mean, SE and percentiles of nutrient intake and prevalence of inadequate intake among male adolescents (n 276), São Paulo, Brazil, 2003

\begin{tabular}{|c|c|c|c|c|c|c|c|c|c|}
\hline \multirow[b]{2}{*}{ Nutrient } & \multirow[b]{2}{*}{$\mathrm{EAR} / \mathrm{Al} / \mathrm{UL}$} & \multirow[b]{2}{*}{ Mean } & \multirow[b]{2}{*}{ SE } & \multicolumn{5}{|c|}{ Percentiles of nutrient intake } & \multirow[b]{2}{*}{$\%$ inad } \\
\hline & & & & 10th & 25th & 50th & 75th & 90th & \\
\hline Vitamin A $(\mu \mathrm{g})^{*}$ & 630 & $491 \cdot 7$ & $68 \cdot 8$ & 221 & 293 & 407 & 585 & 846 & 78 \\
\hline Vitamin C (mg) & 63 & $48 \cdot 2$ & 8.9 & 25 & 34 & 45 & 59 & 75 & 79 \\
\hline Vitamin E (mg)† & 12 & 4.95 & $0 \cdot 1$ & $3 \cdot 77$ & $4 \cdot 25$ & $4 \cdot 86$ & $5 \cdot 56$ & $6 \cdot 27$ & 99 \\
\hline Thiamin (mg) & $1 \cdot 0$ & $1 \cdot 49$ & 0.02 & $1 \cdot 15$ & $1 \cdot 29$ & $1 \cdot 47$ & $1 \cdot 66$ & $1 \cdot 86$ & 2 \\
\hline Riboflavin (mg) & $1 \cdot 1$ & 1.56 & $0 \cdot 12$ & $1 \cdot 13$ & $1 \cdot 29$ & $1 \cdot 15$ & 1.75 & $2 \cdot 08$ & 8 \\
\hline Vitamin $B_{6}(\mathrm{mg})$ & $1 \cdot 1$ & $1 \cdot 36$ & 0.02 & 0.97 & $1 \cdot 14$ & $1 \cdot 34$ & 1.57 & $1 \cdot 8$ & 21 \\
\hline Vitamin $B_{12}(\mu \mathrm{g})$ & $2 \cdot 0$ & $4 \cdot 47$ & 0.67 & $1 \cdot 8$ & $2 \cdot 6$ & $3 \cdot 8$ & $5 \cdot 4$ & $7 \cdot 7$ & 12 \\
\hline$P(\mathrm{mg})$ & 1055 & $1078 \cdot 8$ & $33 \cdot 4$ & 777 & 901 & 1057 & 1233 & 1409 & 49 \\
\hline $\mathrm{Mg}(\mathrm{mg})$ & 340 & $268 \cdot 6$ & $6 \cdot 02$ & 200 & 230 & 265 & 304 & 342 & 89 \\
\hline $\mathrm{Zn}(\mathrm{mg})$ & $8 \cdot 5$ & $11 \cdot 8$ & 0.23 & $7 \cdot 8$ & $9 \cdot 5$ & $11 \cdot 5$ & $13 \cdot 8$ & $16 \cdot 2$ & 15 \\
\hline $\mathrm{Cu}(\mathrm{mg})$ & 0.685 & $1 \cdot 42$ & $0 \cdot 14$ & $0 \cdot 87$ & $1 \cdot 01$ & $1 \cdot 2$ & $1 \cdot 54$ & $2 \cdot 11$ & 1 \\
\hline Se $(\mu \mathrm{g})$ & 45 & $130 \cdot 4$ & $5 \cdot 42$ & 102 & 114 & 129 & 145 & 161 & 0 \\
\hline Niacin (mg)‡ & 12 & 35.9 & $0 \cdot 89$ & $25 \cdot 9$ & $29 \cdot 8$ & 34.9 & $40 \cdot 9$ & $47 \cdot 2$ & 0 \\
\hline Vitamin D $(\mu \mathrm{g})$ & $5 \S$ & $2 \cdot 86$ & $0 \cdot 37$ & $1 \cdot 32$ & $1 \cdot 87$ & $2 \cdot 62$ & 3.59 & $4 \cdot 71$ & - \\
\hline Vitamin $\mathrm{K}(\mu \mathrm{g})$ & $75 \S$ & $79 \cdot 3$ & $2 \cdot 9$ & 47 & 58 & 73 & 93 & 119 & - \\
\hline $\mathrm{Ca}(\mathrm{mg})$ & $1300 \S$ & $549 \cdot 2$ & $69 \cdot 2$ & 323 & 406 & 519 & 660 & 814 & - \\
\hline K (mg) & $4700 \S$ & $2068 \cdot 0$ & $96 \cdot 1$ & 1591 & 1793 & 2041 & 2314 & 2588 & - \\
\hline $\mathrm{Na}(\mathrm{mg})$ & $2300 \|$ & $4019 \cdot 0$ & $209 \cdot 0$ & 3154 & 3541 & 3993 & 4469 & 4918 & - \\
\hline
\end{tabular}

EAR, Estimated Average Requirement; Al, Adequate Intake; UL, Tolerable Upper Intake Level; \% inad., prevalence of inadequate intake.

${ }^{*}$ Calculated as retinol activity equivalents.

tCalculated as $\alpha$-tocopherol equivalents.

$\ddagger$ Calculated as niacin equivalents.

\&AI.

IIUL.

of individuals with usual intakes equal to or above the AI value. Na intake was evaluated with respect to the Tolerable Upper Intake Level (UL), which estimates the percentage of a population potentially at risk for adverse effects $^{(17)}$. Inadequate prevalence was further calculated according to categories of per capita family income, parental educational level and overweight status.

Each stratum was composed of participants of both sexes. Therefore, for nutrients with different intake recommendations because of differences in sex, the estimated percentage below or above the EAR was computed as an average of the percentage of sex subgroups comprising the composite group weighted proportionally by population size ${ }^{(4)}$. Differences in prevalence between sexes and strata were verified by a two-sided proportional test $(5 \%$ significance level) using the survey commands of the STATA statistical software package version $9 \cdot 1$ (StataCorp., College Station, TX, USA) to incorporate sampling weights.

\section{Results}

The mean age of the sample was 16.5 (se 0.06) years. The prevalence of overweight was $15 \cdot 0 \%$ among male and $11 \cdot 8 \%$ among female participants $(P=0 \cdot 081)$. The proportion of adolescents with per capita family income $<1$ minimum wage was $63 \%$ for male and $56 \%$ for female participants $(P=0 \cdot 21)$. Most adolescents (67\% male and $62 \%$ female) had parents with a low educational level $(P=0 \cdot 29)$.

A high prevalence of inadequate intake for vitamins $\mathrm{E}, \mathrm{A}$, $\mathrm{C}$ and $\mathrm{B}_{6}$, as well as for $\mathrm{Mg}$ and $\mathrm{P}$, for both sexes is described in Tables 1 and 2. The risk of inadequate intake was low for riboflavin, thiamin, $\mathrm{Se}$, niacin and $\mathrm{Cu}$. For these nutrients, the usual intake was below the EAR for $<15 \%$ of the adolescents. The prevalence of inadequate intakes of $\mathrm{P}$, vitamin $\mathrm{B}_{6}$, thiamin and $\mathrm{Cu}$ was higher in female than in male participants. In contrast, the risk of vitamin $C$ inadequacy was higher in male than in female participants $(P<0 \cdot 05)$.

The proportion of participants with $\mathrm{Ca}$ and $\mathrm{K}$ intakes above the AI values was $<1 \%$ in adolescents of both sexes. With regard to vitamin $\mathrm{D}$, the proportions of male and female adolescents with intakes above the AI values were $7 \%$ and $8 \%$, respectively. For vitamin $\mathrm{K}$, the proportions were $46 \%$ and $43 \%$ for male and female participants, respectively. With respect to $\mathrm{Na}$ intake, 99\% and $86 \%$ of the male and female adolescents, respectively, had intakes higher than the UL value, with no statistically significant difference between the sexes.

The prevalence of inadequate nutrient intake with regard to income, parental educational level and nutritional status is shown in Table 3.

Compared with adolescents from lower-income families, adolescents from higher-income families had a lower prevalence of inadequate intake for vitamins $\mathrm{A}, \mathrm{C}, \mathrm{B}_{6}, \mathrm{~B}_{12}$, $\mathrm{P}, \mathrm{Zn}$, riboflavin and thiamin. Except for $\mathrm{Zn}$ and thiamin, the inadequate intakes of these same nutrients were more prevalent among adolescents categorised into the lower parental educational level group than among those in the higher parental educational level group.

Compared with non-overweight adolescents, overweight adolescents had a higher prevalence of inadequate intake for vitamin $\mathrm{A}, \mathrm{Mg}, \mathrm{P}$, riboflavin and thiamin.

For nutrients with only AI values established, higher income and parental educational level were associated with 
Table 2 Recommended nutrient intake, mean, SE and percentiles of nutrient intakes and prevalence of inadequate intake among female adolescents ( $n$ 249), São Paulo, Brazil, 2003

\begin{tabular}{|c|c|c|c|c|c|c|c|c|c|}
\hline \multirow[b]{2}{*}{ Nutrient } & \multirow[b]{2}{*}{$\mathrm{EAR} / \mathrm{Al} / \mathrm{UL}$} & \multirow[b]{2}{*}{ Mean } & \multirow[b]{2}{*}{$\mathrm{SE}$} & \multicolumn{5}{|c|}{ Percentiles of nutrient intake } & \multirow[b]{2}{*}{ \% inad." } \\
\hline & & & & 10th & 25th & 50th & 75th & 90th & \\
\hline Vitamin $A(\mu \mathrm{g})^{*}$ & 485 & $398 \cdot 0$ & $8 \cdot 4$ & 176 & 256 & 369 & 508 & 658 & 71 \\
\hline Vitamin C (mg) & 56 & $65 \cdot 5$ & $10 \cdot 5$ & 22 & 34 & 53 & 83 & 123 & 53 \\
\hline Vitamin E (mg)t & 12 & $4 \cdot 7$ & 0.31 & $2 \cdot 5$ & $3 \cdot 4$ & $4 \cdot 5$ & 5.9 & $7 \cdot 4$ & 99 \\
\hline Thiamin (mg) & 0.9 & $1 \cdot 26$ & 0.06 & $0 \cdot 82$ & $1 \cdot 01$ & $1 \cdot 24$ & $1 \cdot 5$ & $1 \cdot 75$ & 15 \\
\hline Riboflavin (mg) & 0.9 & $1 \cdot 31$ & 0.02 & 0.87 & 1.05 & $1 \cdot 28$ & 1.54 & $1 \cdot 8$ & 12 \\
\hline Vitamin $B_{6}(\mathrm{mg})$ & $1 \cdot 0$ & $1 \cdot 2$ & 0.03 & $0 \cdot 71$ & 0.91 & $1 \cdot 16$ & $1 \cdot 46$ & $1 \cdot 77$ & 33 \\
\hline Vitamin $B_{12}(\mu \mathrm{g})$ & $2 \cdot 0$ & $3 \cdot \overline{6} 1$ & $0 \cdot 11$ & 1.91 & $2 \cdot 57$ & 3.44 & $4 \cdot 43$ & $5 \cdot 5$ & 11 \\
\hline$P(\mathrm{mg})$ & 1055 & 933.5 & $14 \cdot 05$ & 662 & 774 & 918 & 1078 & 1226 & 71 \\
\hline$M g(m g)$ & 300 & $226 \cdot 9$ & $11 \cdot 67$ & 138 & 173 & 219 & 272 & 326 & 84 \\
\hline $\mathrm{Zn}(\mathrm{mg})$ & $7 \cdot 3$ & $9 \cdot 84$ & 0.22 & $6 \cdot 5$ & $7 \cdot 9$ & $9 \cdot 6$ & 11.6 & $13 \cdot 5$ & 17 \\
\hline $\mathrm{Cu}(\mathrm{mg})$ & 0.685 & $1 \cdot 03$ & 0.05 & 0.71 & 0.84 & 1 & $1 \cdot 2$ & $1 \cdot 42$ & 7 \\
\hline Se $(\mu \mathrm{g})$ & 45 & $107 \cdot 5$ & $1 \cdot 8$ & 78 & 90 & 106 & 123 & 140 & 0 \\
\hline Niacin $(\mathrm{mg}) \ddagger$ & 11 & $29 \cdot 9$ & 0.55 & $22 \cdot 2$ & $25 \cdot 6$ & $29 \cdot 7$ & 34 & $38 \cdot 2$ & 0 \\
\hline Vitamin D $(\mu \mathrm{g})$ & $5 \S$ & $2 \cdot 64$ & $0 \cdot 1$ & 1 & $1 \cdot 53$ & $2 \cdot 3$ & $3 \cdot 36$ & $4 \cdot 67$ & - \\
\hline Vitamin K $(\mu \mathrm{g})$ & $75 \S$ & $76 \cdot 6$ & $1 \cdot 11$ & 38 & 51 & 70 & 95 & 125 & - \\
\hline $\mathrm{Ca}(\mathrm{mg})$ & $1300 \S$ & $520 \cdot 8$ & $42 \cdot 7$ & 290 & 377 & 495 & 636 & 785 & - \\
\hline $\mathrm{K}(\mathrm{mg})$ & $4700 \S$ & $1903 \cdot 0$ & $70 \cdot 4$ & 1315 & 1558 & 1858 & 2199 & 2550 & - \\
\hline $\mathrm{Na}(\mathrm{mg})$ & $2300 \|$ & $3294 \cdot 0$ & $124 \cdot 3$ & 2157 & 2635 & 3225 & 3879 & 4522 & - \\
\hline
\end{tabular}

EAR, Estimated Average Requirement; Al, Adequate Intake; UL, Tolerable Upper Intake Level; \% inad., prevalence of inadequate intake.

${ }^{*}$ Calculated as retinol activity equivalents.

tCalculated as $\alpha$-tocopherol equivalents.

$\ddagger$ Calculated as niacin equivalents.

$\S A$ I.

॥UL.

Table 3 Prevalence of inadequate nutrient intake according to parental educational level, income and nutritional status among adolescents in São Paulo, Brazil, 2003

\begin{tabular}{|c|c|c|c|c|c|c|c|c|c|}
\hline & $\begin{array}{l}\text { Low educational } \\
\text { level }\end{array}$ & $\begin{array}{c}\text { High educational } \\
\text { level }\end{array}$ & $P^{*}$ & $\begin{array}{l}\text { Low } \\
\text { income }\end{array}$ & $\begin{array}{l}\text { High } \\
\text { income }\end{array}$ & $P^{*}$ & Overweight & Non-overweight & $P^{*}$ \\
\hline Vitamin E & 99 & 99 & $1 \cdot 000$ & 99 & 99 & $1 \cdot 000$ & 99 & 99 & $1 \cdot 000$ \\
\hline $\mathrm{Mg}$ & 88 & 86 & 0.502 & 89 & 87 & $0 \cdot 481$ & 93 & 84 & 0.007 \\
\hline Vitamin A & 80 & 69 & 0.004 & 80 & 69 & 0.004 & 91 & 70 & 0.000 \\
\hline Vitamin C & 73 & 52 & 0.000 & 73 & 56 & 0.000 & 70 & 66 & 0.383 \\
\hline $\mathrm{P}$ & 67 & 48 & 0.000 & 70 & 46 & 0.000 & 70 & 58 & 0.011 \\
\hline Vitamin $\mathrm{B}_{6}$ & 31 & 19 & 0.002 & 31 & 19 & 0.002 & 33 & 25 & 0.065 \\
\hline $\mathrm{Zn}$ & 17 & 13 & $0 \cdot 213$ & 20 & 9 & 0.000 & 19 & 15 & 0.264 \\
\hline Thiamin & 8 & 7 & 0.671 & 17 & 6 & 0.000 & 14 & 11 & 0.341 \\
\hline Vitamin $B_{12}$ & 16 & 5 & 0.001 & 11 & 4 & 0.003 & 15 & 8 & 0.016 \\
\hline $\mathrm{Cu}$ & 4 & 5 & 0.585 & 4 & 3 & 0.537 & 16 & 6 & 0.003 \\
\hline Riboflavin & 13 & 5 & 0.002 & 16 & 2 & 0.000 & 6 & 4 & 0.325 \\
\hline $\mathrm{Se}$ & 0 & 0 & - & 0 & 0 & - & 0 & 0 & - \\
\hline Niacin & 0 & 0 & - & 0 & 0 & - & 0 & 0 & - \\
\hline
\end{tabular}

Parental educational level: low, $<8$ full years of education; high, $\geq 8$ eight full years of education. Income: low, $<1$ minimum wage per capita; high, $\geq 1$ one minimum wage per capita.

*Two-sided proportional test.

a higher proportion of adolescents with vitamin $\mathrm{K}$ intake greater than the recommended value. Compared with nonoverweight adolescents, overweight adolescents were more likely to have usual intake levels of vitamins D and K lower than AI values.

\section{Discussion}

The present population-based study, the first to our knowledge, assessed the prevalence of inadequate nutrient intake among adolescents in Brazil and found a high prevalence of inadequate consumption of vitamins $\mathrm{A}, \mathrm{C}, \mathrm{E}$ and
$\mathrm{B}_{6}$, as well as of $\mathrm{Mg}$ and $\mathrm{P}$. In addition, we found that a small proportion of adolescents had Ca intake above the AI value and that $\mathrm{Na}$ intake was above the levels considered safe for most adolescents. We also observed a higher prevalence of inadequate nutrient intake among those in the lower income and lower parental educational level strata compared with those in the higher income and higher parental educational level strata.

The nutrients with a high prevalence of inadequacy in Brazil were the same as those found to be inadequate in US populations assessed using the National Health and Nutrition Examination Survey 2001-2002, although the magnitude of inadequacy in the present study was higher for most of the 
nutrients. For example, in Brazilian male and female adolescents, the prevalence of inadequate intake was $78 \%$ and $71 \%$ for vitamin A, $79 \%$ and $53 \%$ for vitamin $\mathrm{C}$ and $21 \%$ and $33 \%$ for vitamin $\mathrm{B}_{6}$, respectively. In US male and female adolescents, the prevalence of inadequate intake was $55 \%$ and $54 \%$ for vitamin $\mathrm{A}, 26 \%$ and $42 \%$ for vitamin C and $<3 \%$ and $16 \%$ for vitamin $\mathrm{B}_{6}$, respectively ${ }^{(4)}$.

The chosen criterion of nutritional adequacy or adverse effects on which the DRI is based is different for each nutrient as identified in the DRI nutrient reports. In the case of adolescents, dietary requirements are high because of growth spurts, puberty and cognitive development ${ }^{(18)}$. Furthermore, vitamins $\mathrm{A}, \mathrm{C}$ and $\mathrm{E}$, which are nutrients with a high prevalence of inadequate intake among the adolescents in the present study, have antioxidant functions and can be protective against diseases ${ }^{(19,20)}$. Previously, the highest quintiles of vitamin $\mathrm{E}$ intake and vegetable fats during adolescence were found to be associated with a reduced risk of breast cancer during adulthood ${ }^{(21)}$. Moreover, a combined intake of vitamins $\mathrm{C}$ and $\mathrm{E}$ had an effect on the reduction of atherosclerosis progression in hypercholesterolaemic subjects ${ }^{(22)}$. In addition to the inadequate intake of these nutrients, a higher intake of $\mathrm{Na}$ was also related to an increased risk of $\mathrm{CVD}^{(23)}$.

Our results add evidence that socio-economic factors are determinants of dietary patterns. The cost and access to foods might partially explain this phenomenon. Diets that are comprised of foods with a high nutrient concentration and low energy density are usually more expensive than those based on refined grains, added sugar and fats ${ }^{(24)}$. According to data from a national survey on household food availability in Brazil, the relative intakes of fruit, vegetables, milk and meat increase with income, although the consumption of fresh vegetables was shown to be modest even in the richest stratum ${ }^{(3)}$. The same effect was observed with regard to parental educational level: those in the lowest stratum of parental educational level and those in the low-income group were more likely to have an inadequate intake for almost all nutrients. One plausible explanation is that the heads of households with higher levels of education have more knowledge about healthy habits and are therefore able to adopt healthier eating patterns and influence their children's food choices ${ }^{(25)}$.

The assessment of the prevalence of inadequate nutrient intake requires information regarding the population's distribution of usual nutrient intakes, which can be estimated using statistical methods. If intake distributions are not properly adjusted for both within-person variability and survey-related effects, the prevalence of nutrient inadequacy will be incorrectly estimated ${ }^{(1,26)}$. Although several methods have been proposed for the adjustment of dietary data, we used the method that is one of the most efficient for the estimation of the usual intake distribution ${ }^{(15)}$. Furthermore, this method was recommended by both the IOM and WHO to estimate the prevalence of inadequate nutrient intake ${ }^{(1,27)}$.
The external within-person variance components were used to adjust the intake distribution, and this adjustment may be a possible limitation in the study. However, this procedure is recommended for estimating the distribution of usual nutrient intake when only a single, short-term dietary measurement for each participant is available ${ }^{(12,13)}$. Moreover, the variance components were generated from dietary measurements replicated in the same individuals from the initial sample, although within a 4-year interval. In this regard, we can argue that Brazil has experienced political and economic stability during this period and that no events occurred that could have led to a change in food patterns. Another limitation of the present study may be the misreporting or under-reporting of dietary intake. Nevertheless, these errors may have been minimised by the interviewers' training, information checking and by the adoption of the standardised multiple-pass approach.

The present population-based study used methods proposed by the IOM and WHO and found a high prevalence of inadequate nutrient intake, which may be related to the development of chronic diseases including cancer and CVD, in an adolescent population. Participants categorised into lower income, lower parental educational level and overweight groups appear to be at increased risk of inadequate intake for some nutrients.

\section{Acknowledgements}

The authors thank The State of São Paulo Research Foundation (FAPSEP; process no. 07/52119-0, 07/51489-9, 98/140999-7) and the Brazilian National Research Council (CNPq; process no. 502948/2003-5) for the financial support provided to them. The authors have no conflict of interest to declare. C.L.G.C., D.M.L.M. and R.M.F. participated in planning and study design and in review of the manuscript; E.V.J. conducted the analyses; E.V.J. and D.M.L.M. were involved in conception of the manuscript.

\section{References}

1. Institute of Medicine, Food and Nutrition Board (2000) Dietary Reference Intakes: Applications in Dietary Assessment. Washington, DC: National Academy Press.

2. Viteri EF \& Gonzales H (2002) Adverse outcomes of poor micronutrients status in childhood and adolescence. Nutr Rev 60, S46-S52.

3. Levy-Costa RB, Sichieri R, Pontes NS et al. (2005) Household food availability in Brazil: distribution and trends (1974-2003). Rev Saude Publica 39, 530-540.

4. Moshfegh A, Goldman J \& Cleveland L (2005) What We Eat in America. NHANES 2001-2002: Usual Nutrient Intakes from Food Compared to Dietary Reference Intakes. Washington, DC: USDA/ARS.

5. Suitor CW \& Gleason PM (2002) Using dietary reference intake-based methods to estimate the prevalence of inadequate nutrient intake among school-aged children. J Am Diet Assoc 102, 530-536. 
6. Affenito SG, Thompson DR, Franko DL et al. (2007) Longitudinal assessment of micronutrient intake among African-American and white girls: The National Heart, Lung, and Blood Institute Growth and Health Study. J Am Diet Assoc 107, 1113-1123.

7. Drewnowsky A \& Darmon N (2005) Food choice and diet costs: an economic analyses. J Nutr 135, 900-904.

8. Castro MA, Barros RR, Bueno MB et al. (2009) Trans fatty acid intake among the population of the city of São Paulo, Brazil. Rev Saude Publica 43, 991-997.

9. De Onis M, Onyango AW, Borghi E et al. (2007) Development of a WHO growth reference for school-aged children and adolescents. Bull World Health Organ 85, 660-667.

10. Thompson FE \& Byers T (1994) Dietary assessment resource manual. J Nutr 124, Suppl. 11, S2245-S2317.

11. Nusser SM, Carriquiry AL, Dodd KW et al. (1996) A semiparametric transformation approach to estimating usual daily intake distributions. J Am Stat Assoc 91, 1440-1449.

12. Jahns L, Arab L, Carriquiry AL et al. (2005) The use of external within-person variance estimates to adjust nutrient intake distributions over time and across populations. Public Health Nutr 8, 69-76.

13. Murphy SP, Guenther PM \& Kretsch MJ (2006) Using the dietary reference intakes to assess intakes of groups: pitfalls to avoid. J Am Diet Assoc 106, 1550-1553.

14. Dwyer J, Picciano MF \& Raiten DJ (2003) Estimation of usual intakes: What We Eat in America-NHANES. $J$ Nutr 133, Suppl. 2, S609-S623.

15. Hoffman K, Boing H, Dufour A et al. (2002) Estimating the distribution of usual dietary intake by short-term measurements. Eur J Clin Nutr 56, Suppl. 2, S53-S62.

16. Beaton GH (1994) Criteria of an adequate diet. In Modern Nutrition in Health and Disease, 8th ed., pp. 1491-1505 [ME Shils, JA Olson and M Shike, editors]. Philadelphia, PA: Lea \& Febiger.
17. Institute of Medicine, Food and Nutrition Board (2000) Dietary Reference Intakes for Water, Potassium, Sodium, Chloride, and Sulfate. Washington, DC: National Academy Press.

18. DiMeglio G (2000) Nutrition in adolescence. Pediatr Rev 21, 32-38.

19. Institute of Medicine, Food and Nutrition Board (2000) Dietary Reference Intakes for Vitamin A, Vitamin $K$, Arsenic, Boron, Chromium, Copper, Iodine, Iron, Manganese, Molybdenum, Nickel, Silicon, Vanadium, and Zinc. Washington, DC: National Academy Press.

20. Institute of Medicine, Food and Nutrition Board (2000) Dietary Reference Intakes for Vitamin C, Vitamin E, Selenium, and Carotenoids. Washington, DC: National Academy Press.

21. Frazier AL, Li L, Cho E et al. (2004) Adolescent diet and risk of breast cancer. Cancer Causes Control 15, 73-82.

22. Salonen RM, Nyyssönen K, Kaikkonen J et al. (2003) Sixyear effect of combined vitamin $\mathrm{C}$ and $\mathrm{E}$ supplementation on atherosclerotic progression: The Antioxidant Supplementation in Atherosclerosis Prevention (ASAP) Study. Circulation 107, 947-953.

23. Cook NR, Cutler AJ, Obarzanek E et al. (2007) Long term effects of dietary sodium reduction on cardiovascular disease outcomes: observational follow-up of the trials of hypertension prevention (TOHP). BMJ 334, 885-893.

24. Drewnowski A, Darmon N \& Briend A (2004) Replacing fats and sweets with vegetables and fruit - a question of cost. Am J Public Health 94, 1555-1559.

25. Xie B, Gilliland FD, Li YF et al. (2003) Effects of ethnicity, family income, and education on dietary intake among adolescents. Prev Med 36, 30-40.

26. Carriquiry AL (2003) Estimation of usual distribution of nutrients and foods. J Nutr 133, 601S-608S.

27. Murphy SP \& Vorster HH (2007) Methods for using nutrient intake values (NIVs) to assess or plan nutrient intakes. Food Nutr Bull 28, Suppl. 1, 51-60. 